\title{
Medicalização Escolar em Periódicos de Psicologia e Educação no Triênio 2010-2012
}

\author{
Cláudia Ap. Valderramas Gomes - Universidade Estadual Paulista Júlio de Mesquita Filho, São Paulo, Brasil \\ Naeli Simoni-Castro - Universidade Estadual Paulista Júlio de Mesquita Filho, São Paulo, Brasil
}

\begin{abstract}
Resumo
O artigo apresenta uma análise da produção científica sobre a medicalização da educação. Teve como objetivo identificar a presença de posicionamentos críticos e não críticos nos estudos, adotando como críticas as concepções que não reduzem a complexidade humana a características individuais e/ou biológicas e que evidenciam a essência dos processos históricos e compromissos sociais assumidos pelo conhecimento científico. Foram selecionados sessenta e um artigos, publicados entre 2010-2012 em periódicos com qualificação A1, A2 e B1 nas áreas de Psicologia e Educação, que apresentavam como escopo as denominadas dificuldades escolares e elementos correlatos à medicalização da educação. A análise empregou categorias que consideraram o viés crítico ou acrítico, explicitados por meio do aporte teórico que definiu o objeto de estudo, dos instrumentos e procedimentos metodológicos utilizados. Os resultados indicaram um número reduzido de estudos críticos, requerendo a necessidade de novas pesquisas que contribuam para a superação de concepções e práticas medicalizantes.

Palavras-chave: estado da arte, psicologia, educação, medicalização
\end{abstract}

Medicalization of Education in Journal of Psychology and Education in Triennium 2010-2012

\begin{abstract}
The article presents an analysis of the scientific literature on the medicalization of education and aimed to identify the presence of critical and non-critical studies, adopting conceptions that do not reduce human complexity to its biological perspective, but shows the essence of historical processes and social commitments made by scientific knowledge. A total of 60 articles were selected, published between 2010-2012 in journals with qualification A1, A2 and B1 in the fields of psychology and education, concerning to the so-called learning problems or correlates and medicalization of education. For the analysis, we used categories considered critical or uncritical, which is explained by the theoretical framework that defined the object of study, the methodological tools and procedures used. The results indicated a small number of critical studies, what indicates the need for further studies that contribute to overcome medicalized conceptions and practices.

Keywords: State of the art; Psychology; Education; Medicalization
\end{abstract}

Medicalización Escolar en Periódicos de Psicología y Educación en el Trienio 2010-2012

\section{Resumen}

El artículo presenta un análisis de producción científica sobre la medicalización de la educación. La investigación tuvo como objetivo identificar la presencia de posicionamientos críticos y no-críticos en los estudios, adoptando como críticas las concepciones que no reducen la complejidad humana a las características individuales y/o biológicas y que evidencian la esencia de los procesos históricos y compromisos sociales asumidos por el conocimiento científico. Fueron seleccionados 61 artículos, publicados entre 2010-2012 en periódicos con calificación A1, A2 y B1 en las áreas de psicología y educación, que presentaban como ámbito las denominadas dificultades escolares y elementos relacionados con la medicalización de la educación. El análisis utilizó categorías que consideraban el punto de vista crítico o acrítico, explicitadas por medio del aporte teórico que definió el objeto del estudio, de los instrumentos y los procedimientos metodológicos utilizados. Los resultados indicaron un número reducido de estudios críticos, requiriendo la necesidad de nuevas investigaciones que contribuyan para la superación de concepciones y prácticas medicalizantes.

Palabras-clave: Estado del arte; Psicología; Educación; Medicalización.

\section{Introdução}

A tarefa de pensar o lugar da Psicologia no enfretamento de alguns dilemas contemporâneos na interface com a Educação coloca a medicalização como o mecanismo atualmente utilizado para dissimular os processos de produção do fracasso e exclusão educacional. A medicalização refere-se a um recurso utilizado para transformar questões de origem eminentemente social e política em demandas médicas, isto é, utiliza-se do modelo biomédico, sustentado no método clínico, para abordar problemas de ordem socioeconômica e cultural (Collares \& Moysés, 1994). Quando aplicado à compreensão do comportamento humano, conduz a uma visão individualizada que converte demandas sociais em biológicas. $\mathrm{Na}$ educação escolar, caracterizase por uma tendência a conceber o não aprender ou não-se-comportar-na-escola como consequências de transtornos de aprendizagem e/ou de comportamento. Portanto, as tentativas de lidar com casos de fracasso escolar como se eles fossem uma patologia do sujeito são exemplos de medicalização. 
Essas dificuldades relacionadas a não aprendizagem ou ao comportamento inadequado presentes na escola estão entre os principais motivos de encaminhamento de crianças para atendimento especializado nos sistemas públicos de saúde, educação e assistência social, clínicas-escolas de Psicologia e consultórios particulares, conforme pesquisas nos campos da educação e da saúde (Angelucci \& Souza, 2010, p.07). Em alguns estudos (Zibetti, Souza, \& Queiróz, 2010; Caliman, 2010; Eidt \& Tuleski, 2010; Leite \& Tuleski, 2011; Meira, 2012a; Rossato \& Leonardo, 2012; Rodríguez, Campos, \& Fernandes, 2012), os autores assumem um posicionamento crítico em relação às dificuldades enfrentadas pelas crianças no processo educacional e ao fenômeno da medicalização, buscando na Filosofia, na Sociologia, na Medicina, na Psicologia e em outras áreas do conhecimento, elementos teóricos capazes de romper com paradigmas contrários a história que ocultam as origens da medicalização no contexto escolar. Ao analisar criticamente a necessidade de avaliação, diagnóstico e indicação de tratamento individual em casos de dificuldades escolares, esses estudos denunciam uma estratégia ideológica organizada para dissimular mecanismos externos e internos à escola, produtores, ou intensificadores, da não aprendizagem em crianças, principalmente aquelas advindas dos segmentos mais pobres da população. Esse tipo de análise, que evidencia os mecanismos responsáveis pela culpabilização individual em detrimento de fatores históricos e sociais na produção da incapacidade humana, alerta para a necessidade de estudos que sejam capazes de avançar da aparência em direção à essência dos fenômenos, superando a naturalização das condições de vida, de educação, de aprendizagem e desenvolvimento.

Concepções críticas em relação à Psicologia e à Educação, bem como às interfaces possíveis entre ambas, começaram a ser anunciadas no final dos anos 70 e início da década de 1980. Desde então estudiosos da área (Patto, 1984, 1999, 2000; Meira, 2000, 2003, 2012a; Souza, 2010) têm se dedicado a caracterizar esse tipo de análise. Meira (2003) argumenta que:

(...) um pensamento que se pretende critico deve contemplar, pelo menos, os seguintes elementos principais: reflexão e método que apreendam o movimento das contradições dos fenômenos, como fatos sociais concretos, sintese de múltiplas determinações (...). Crítica do conhecimento que possa apontar para o caráter ideológico da ciência (...). Denúncia da degradação bumana, da alienação e da heteronomia bumana nas condições postas pelo capitalismo (...). Possibilidade de ser utilizado como instrumento no processo de transformação social. (p.15-16, grifo nosso).
Outro argumento utilizado pelos estudos críticos diz respeito à necessidade de explicitar o verdadeiro papel da ciência na constituição de um modelo de pensamento em relação à condição humana. Ao realizar a discussão acerca da Psicologia sob a ótica da abordagem crítica à Psicologia Científica Patto (1984, p.79) apoia-se em Martins $(1977$, p. 2) para reiterar:

(...) a possibilidade de uma análise crítica dos rumos tomados por uma ciência, no sentido mais profundo que o termo "crítica" pode assumir: o de "situar o conbecimento, ir à sua raiz, definir os seus compromissos sociais e históricos, localizar a perspectiva que o construiu, descobrir a maneira de pensar e interpretar a vida social da classe que apresenta esse conbecimento como universal".

Em seu texto sobre a tarefa da crítica na Psicologia, Meira (2012b), além de apresentar e discutir cada um dos elementos que caracterizam o pensamento crítico, com base nos fundamentos do materialismo histórico e dialético, coloca à Psicologia a tarefa de desvelar as inconsistências teóricas que permanecem dificultando práticas profissionais críticas comprometidas com o pleno desenvolvimento humano. Nesse mesmo trabalho, a autora (2012b, p. 17) reafirma a concepção de que a estrutura econômica da sociedade constitui a base real que explica “(...) toda a superestrutura integrada pelas instituições jurídicas e políticas, bem como as diferentes ideologias de cada período histórico." Afirma ainda que o pensamento crítico se constitui em um instrumento teórico fundamental para o processo de transformação social, mas, para isso, os elementos constitutivos dele devem ser orientadores das possibilidades de incorporá-lo no interior da ciência psicológica, o que significa romper com visões que naturalizam o fenômeno psicológico, entendendo-o em sua articulação com o contexto histórico, social e cultural.

Uma perspectiva crítica acerca da medicalização não pode deixar de contemplar a interconexão entre medicalização e ideologia ${ }^{1}$, evidenciando que existem duas vertentes ou duas posições distintas no que tange ao debate sobre os transtornos de aprendizagem ou sobre a medicalização da educação. Não se trata de uma questão meramente técnica, mas nutrida por visões de mundo, de ciência e, nesse caso específico, de processos de aprendizagem e de desenvolvimento humano.

A questão ideológica presente no fenômeno da medicalização refere-se ao fato dele estar envolto

\footnotetext{
${ }^{1}$ Tomamos como referência teórica sobre ideologia as reflexões de Marilena Chauí (1980, 1997).

Psico-USF, Bragança Paulista, v. 22, n. 3, p. 425-436, set./der. 2017
} 
por um discurso que reduz a complexidade humana a características individuais ou biológicas, ou seja, uma interpretação equivocada das diferenças. Uma característica essencial do discurso ideológico é, de acordo com Chauí (1980), a existência de "lacunas", "espaços em branco" ou, ainda, de "silêncios" que ele deve conter sob pena de perder sua consistência interna, ou seja, na qualidade de um discurso que deve ocultar ao invés de manifestar, esses "vazios" tornam-se responsáveis pela sua coesão. E são essas lacunas que sustentam aquilo que ele deve encobrir, caso contrário, não seria ideológico.

Do ponto de vista da saúde-doença, os preceitos têm sofrido constantes mudanças, mas a ciência ainda é referida como a principal produtora de verdades. Guarido (2010, p.29) afirma que "os enunciados científicos adquirem em nosso tempo um valor de verdade (...) valem como saber exclusivo na elucidação dos problemas impostos por seu objeto, ainda que este seja o homem e sua vida".

Assim posto, cabe mencionar que o fenômeno da medicalização tem como uma das suas características o fato de as práticas diagnósticas orientarem-se por pressupostos de normalidade, padrões de comportamento considerados típicos, regulares, previsíveis, ou seja, instituídos e sustentados por uma ideologia que demarca quais as maneiras de pensar, de sentir ou agir são aceitáveis e quais têm de ser remediadas, modificadas e medicadas.

Como alguns dos fatores que contribuem para a expansão da medicalização estão o modelo hegemônico de atenção à saúde centrada no sintoma, na doença desconectada da integralidade da pessoa, o poder econômico da indústria farmacêutica que faz com que a saúde seja tratada como mercadoria e a dificuldade do profissional da saúde em abrir mão do poder de medicar derivado de um saber técnico. É preciso considerar que a medicalização se origina da ação de especialistas da área médica, que apontam a existência de crianças-problema e se colocam como profissionais detentores de um conhecimento científico necessário para a solução. Existe um mecanismo de construção de demanda com o fortalecimento da ciência moderna e, a partir da medicina a biologização de questões sociais, passou a ser a resposta da sociedade para diversos conflitos sociais.

Diante de tantos artifícios para distinguir o diferente, vinculando singularidades a patologias, intensificam-se os diagnósticos e o número de indivíduos considerados atípicos. A eficácia desse processo também se revela na produção de novas maneiras de rotular, ou seja, o que no passado era concebido como da ordem natural da vida - o sofrimento, a tristeza ou a ansiedade - atualmente apresentam-se como patologias e são descritos como distúrbios ou transtornos. As instituições e organizações são equipamentos sociais também sujeitos aos mesmos mecanismos e agentes de tantos outros preceitos que regularizam, fazendo distinção entre o comportamento esperado e o não aceito.

No terreno da educação escolar, algumas análises superficiais reduzem a problemática do ensinar e do aprender a questões de natureza individual e biológica e a associação de problemas e dificuldades escolares enfrentados pelas crianças a disfunções neurológicas (dislexia, transtorno de déficit de atenção, hiperatividade), têm demandado um tratamento que inclui a prescrição e administração de medicamentos fartamente disponíveis no mercado farmacológico. Guarido (2010) comenta o resultado dessa prática medicalizante afirmando que:

\section{(...) um número cada vez maior de crianças e adolescentes e, em idade cada vez mais precoce, é medicado de forma a tentar sanar sintomas das crianças, sem considerar o contexto no qual se apresentam; não levando em conta, também, as com- plexas manifestações singulares de cada sujeito. Assim, no lugar de considerar um psiquismo em estruturação, supõe-se um déficit neurológico. (p. 29)}

Entende-se que a superação de práticas medicalizantes que permanecem entranhadas no discurso científico requer uma permanente e necessária articulação de elementos teóricos a uma prática consciente com vistas à superação dos diferentes processos de patologização da vida que tem se fortalecido e expandido para o interior da escola. Assim, o escopo desta pesquisa foi propor uma investigação capaz de identificar as principais contribuições que têm emergido dos estudos científicos nas áreas da psicologia e da educação em periódicos inscritos na plataforma Coordenação de Aperfeiçoamento de Pessoal de nível Superior - CAPES - e, com base nos artigos analisados, compreender se há prevalência de manifestações críticas em relação ao processo de medicalização da educação.

\section{Método}

O estado da arte, também denominado estado do conhecimento, tem sido o aporte para um número expressivo de pesquisas e se caracteriza pelo caráter bibliográfico com objetivo primordial de mapear e 
discutir uma determinada “(...) produção acadêmica em diferentes campos do conhecimento, tentando responder que aspectos e dimensões vêm sendo destacados e privilegiados em diferentes épocas e lugares, de que formas e em que condições têm sido produzidas (...) em publicações em periódicos". (Ferreira, 2002, p. 258). Angelucci, Kalmus, Paparelli e Patto, (2004) destaca que a importância das pesquisas do estado das coisas vigente numa área do conhecimento está além de detectar teoria e métodos dominantes e revelar as relações das pesquisas recentes com as anteriores, mas permite a superação de concepções, assim como evita a cristalização do conhecimento que apresenta, como essência, o constante movimento.

\section{Compilação de Periódicos, Artigos e Construção das Categorias de Análise}

A pesquisa sobre as questões atinentes aos denominados problemas de aprendizagem e à medicalização escolar levou em conta o debate teórico-prático nas áreas de psicologia e educação. $\mathrm{O}$ estudo propôs uma revisão da produção científica dessa temática em periódicos de circulação nacional e internacional. ${ }^{2}$ Delimitando o corpus do estudo a artigos publicados em língua portuguesa e espanhola no triênio 2010-2012 em revistas das áreas de psicologia e educação com qualificação A1, A2 e B1, disponíveis no formato on-line.

Foi contabilizado um total de trezentos e cinquenta e cinco periódicos, assim distribuídos: duzentos e cinquenta e sete de Educação; e noventa e oito de Psicologia. A partir dessa triagem foram selecionados artigos pertencentes às referidas revistas que apresentavam como foco de pesquisa a medicalização escolar, dificuldades de aprendizagem e outras terminologias correlatas ao fracasso escolar, utilizando-se o seguinte procedimento de coleta dos dados: 1 - Abertura do número da revista 3 ; 2 - Leitura dos títulos dos trabalhos; 3 - Seleção dos artigos relacionados com a grande temática; 4 - Leitura integral dos resumos desses artigos previamente selecionados. Tomou-se como critério que a não utilização de palavras-chave como procedimento de filtragem traria maior confiabilidade à pesquisa, visto que a leitura e análise dos resumos

\footnotetext{
${ }^{2}$ Segundo a avaliação da CAPES (Coordenação de Aperfeiçoamento de Pessoal de Nível Superior), referente ao Trienal 2013.

${ }^{3}$ Esse procedimento requeria pesquisar os sítios eletrônicos de cada revista, a partir do Número Internacional Normalizado das Publicações em Série ISSN - (International Standard Serial Number) correspondente, evitando possíveis confusões entre periódicos científicos de mesmo nome.
}

poderiam assegurar a aproximação aos artigos de real interesse, possibilitando a seleção da temática em questão e evitando a perda daqueles que, por acaso, fossem importantes para o estudo.

Tal procedimento culminou com a seleção de 31 revistas, dentro das quais foram eleitos sessenta e um artigos, dispostos nas respectivas áreas do conhecimento. Após a leitura integral de todos os estudos, procedeu-se a construção das categorias de análise, as quais pretendiam indicar a postura teórico-científica explicitada nos estudos, corroborando ou contrapondo-se ao processo de medicalização, ou seja, apresentando um posicionamento crítico em relação ao mesmo. Assim foram construídas três grandes categorias temáticas, todas desdobradas em subcategorias. Por meio da primeira - Conceptualização e definição dos problemas/transtornos/distúrbios - procurou-se identificar o aporte utilizado pelos autores para a definição de seu objeto de estudo, tendo como foco os transtornos de aprendizagem/comportamento (dislexia, discalculia, transtorno de déficit de atenção, hiperatividade, etc.).

A segunda grande categoria versou sobre a questão metodológica, por meio da qual se procurou entender qual(s) o(s) instrumento(s) e procedimento(s) metodológicos foi utilizado(s) nos estudos para alcançar o(s) objetivo(s) proposto(s) e a terceira e última grande categoria abordou modos de intervenção, por meio dela se buscou entender qual foi a solução proposta ou os modos de enfrentamento encontrados pelo estudo.

\section{Resultados e Discussão}

Dentre os sessenta e um artigos analisados, apenas quinze apresentaram um posicionamento crítico frente à medicalização escolar, o que representa um percentual de 25\%: sendo nove de Psicologia (A1-1; A2-3 e B1-5) e seis da área da Educação (A1-1; A2-1 e B1-4). O estudo revelou que, apesar de muitas revistas apresentarem um número expressivo de artigos sobre a temática investigada ao longo do triênio 2010-2012, poucos periódicos se destacaram pelo número de estudos com viés crítico.

Nesse sentido, indagaram-se quais seriam os determinantes desses achados: o fenômeno da medicalização ainda se encontra adstrito às publicações da área médica, havendo pouca iniciativa para estudos e pesquisas nas áreas da psicologia e da educação? Os pressupostos teórico, filosófico e metodológico escolhidos para nortear os trabalhos no período e nas duas áreas pesquisadas, ainda se mantém atrelados a uma vertente contrária a história, distante de uma concepção crítica de sujeito e 
de ciência? Ou ainda, as publicações que se aproximam de uma perspectiva crítica no tratamento da temática da medicalização da vida e, especialmente da educação, estão circunscritas a outros espaços de publicação que não o selecionado para essa pesquisa?

$\mathrm{Na}$ primeira categoria - Conceptualização e definição de problemas de aprendizagem/transtorno do comportamento - os artigos revisados nas áreas de psicologia e educação (A1 e A2), expõe a somatória de trinta estudos compilados no período de três anos. Dentro desse recorte, foram identificados oito artigos que não definem os termos utilizados quando abordam a temática dos problemas de aprendizagem/comportamento, ou ainda, artigos que, embora definam o fazem de forma muito vaga sem demonstrar, claramente ao leitor, quais elementos integram o conceito acerca desses fenômenos. Além desses, outros sete artigos se embasam no DSM/CID-10/ APA e utilizam definições amparadas por padronizações, com vistas à normalidade e anormalidade. Assim, percebese que a metade desses estudos tende a compreender os transtornos, tomando por base o que está prescrito nos manuais, aproximando-se de uma definição orgânica das doenças e reduzindo-as à dimensão corporal, centrada no indivíduo. Vale ressaltar que, via de regra, a dificuldade de aprendizagem mais estudada é o transtorno de déficit de atenção e hiperatividade - TDAH - correntemente tratada como (dis)função biológica, cuja maturação orgânica encontra-se comprometida a ponto de interferir na aprendizagem desses sujeitos.

Acerca desses conceitos imprecisos, concorda-se com Viégas e Oliveira (2014) que, citando Moysés e Collares (2010), afirmam que há cento e treze anos são formuladas hipóteses neurológicas de transtornos que acometeriam a aprendizagem e/ou o comportamento, as quais jamais foram comprovadas, e cujos conceitos continuam insólitos e inconclusos. Esses conceitos vagos corroboram a percepção acrítica frente ao fenômeno da medicalização, como referido por Meira (2012a, p. 138): “(...) tanto a descrição do transtorno quanto o tipo de sintomas que sustentam o seu diagnóstico revelam a falta de uma análise crítica sobre as relações entre os fenômenos que ocorrem na educação e o contexto histórico-social que a determina". Assim, pode-se inferir que predomina, no conjunto dos textos analisados, uma discussão dos processos do não aprender e/ou não se comportar na escola como algo alocado no sujeito aprendiz.

Para se contrapor a esse reducionismo biológico, a vertente de estudos mais críticos reafirma que a presença de mecanismos ideológicos intensifica um olhar não histórico na produção das dificuldades escolares. É o caso do estudo em que Meira (2012a) expõe a necessidade de romper com visões que naturalizam o fenômeno psicológico, entendendo-o em sua articulação com o contexto histórico, social e cultural. A questão ideológica presente no fenômeno da medicalização refere-se ao fato dele estar envolto por um discurso que reduz a complexidade humana a características individuais ou biológicas, ou seja, uma interpretação equivocada das diferenças.

No conjunto de artigos analisados no estrato B1 de Psicologia e Educação, foi encontrado um número bem expressivo de estudos (nove) que buscam uma concepção histórica e social dos transtornos de aprendizagem. Dentre esses, cinco estão em psicologia e quatro na área de educação e todos foram conclusivos quanto ao fato de se tratarem de artigos críticos, buscando argumentações teórico-filosóficas em autores da escola Foucaultiana e da Psicologia Histórico-Cultural que aludiam a um sujeito cultural, constituído na inter -relação com a realidade social. Dessa forma, fez-se presente em tais estudos, o aporte de teorias que reconhecem que a aprendizagem e o desenvolvimento da criança não podem ser abstraídos da realidade concreta, tanto no que tange a aspectos macroestruturais como a economia vigente e o cenário político, quanto ao funcionamento institucional presente nas escolas e/ou no cotidiano familiar.

Também fora observado, nesse estrato, um número muito significativo de estudos (sete artigos) que recorrem aos compêndios e manuais diagnósti$\cos ^{4}$ como forma de identificar elementos e sintomas e classificar processos psíquicos e comportamentais visando definir os supostos transtornos. Vale ressaltar que, mesmo considerando a medicação apenas como um capítulo do processo de medicalização, tem-se assistido a um aumento da prescrição de medicamentos para crianças e jovens, dado que registra uma relação direta com o fato de o diagnóstico psiquiátrico ter deixado de ser uma questão exclusivamente técnica, circunscrita à área médica, passando a circular na vida cotidiana demandando a participação das pessoas, em diferentes contextos, na identificação da presença ou ausência de determinadas doenças, ou seja, o

\footnotetext{
${ }^{4}$ Artigos que trazem vínculos com DSM (Diagnostic and Statistical Manual of Mental Disorders)/CID-10 (Classificação Internacional de Doenças)/APA (American Psychological Association) são aqueles que se pautam em protocolos listados que definem modelos típicos de comportamento.
} 
diagnóstico psiquiátrico passou a ser uma maneira de subjetivar nossas vivências emocionais.

Nesse caso, a questão da medicalização está muito ligada à proliferação de diagnósticos e isso tem se consolidado na história recente, mais especificamente ao longo do século XX, com a padronização de sintomas trazida pelas sucessivas edições do Manual Diagnóstico e Estatístico de transtornos mentais da Associação Psiquiátrica Americana - DSMs (1952, 1968, 1980, 1989, 1994, 2013) - que se institui a partir de uma descrição baseada em critérios relativamente estáveis e que têm uma validade prática e instrumental, ou seja, são classificações baseadas em descrições de situações preestabelecidas. Tal como um dicionário de rótulos para a descrição de um quadro clínico, os transtornos mentais passaram a ser classificados e analisados independentemente das particularidades do sujeito; o foco ultrapassa os sujeitos singulares para o conjunto de sintomas relativo aos transtornos.

No conjunto de sete artigos, acima referidos, a maioria amparada por testes e a comparação entre grupos, o enquadre teórico indica a tentativa de equiparação entre os sujeitos: "A partir de uma noção organicista, os sujeitos são vistos como indivíduos 'homogêneos' que devem seguir, invariavelmente, o mesmo ritmo de aprendizagem" (Massi \& Santana, 2011, p. 408), e como tal é aceitável, dentro desse modelo de pensamento, compará-los e defini-los como estando à margem do padrão. Segundo Collares e Moysés (1996) essa prática vai ao encontro de uma ciência positiva:

A ciência não tem se preocupado com o respeito às diferenças, ao contrário. Aplicar a todos, indistintamente, o mesmo padrão de desenvolvimento revela a concepção subjacente de saúdel doença como processo único, contínuo, apenas com diferenças quantitativas entre o momento estático da saúde e o da doença. Reforça-se, assim, a filosofia positivista. (p. 129)

Nota-se que um aporte teórico subjacente a uma concepção organicista de aprendizagem e de desenvolvimento humano pode reforçar uma prática adaptacionista e de culpabilização do sujeito dada a sua incapacidade de aprender ou se comportar na escola. Castilho (2012, p. 23), reitera que o conceito de dificuldade de aprendizagem encontrou amparo científico na psiquiatria e na psicologia atual, mas foi uma invenção da pedagogia do final do século XIX “(...) que surgiu a partir da reforma do sistema educativo cujo objetivo é a generalização da educação e a avaliação das aptidões linguísticas, matemáticas, de leitura e de escrita em um curto espaço de tempo".
Com o suporte de pesquisas que buscam referendar o funcionamento psíquico em bases orgânicas, reconhecendo o fundamento biológico para os sofrimentos psíquicos, a aproximação entre fenômenos mentais e doenças orgânicas contribui para colocar a biologia como o núcleo da patologia na atualidade; a legitimação da psiquiatria e da psicologia, os adventos dos manuais e dos testes psicométricos, o apoio e financiamento da indústria farmacêutica e a utilização da mídia para disseminar essas patologias e teorizações, os transtornos e patologias que incluem problemas de aprendizagem e de comportamento excederam o domínio de conhecimento dos especialistas e adentraram a educação familiar solidificando, no discurso e atitude dos pais, uma concepção e prática medicalizantes. De uma forma geral, é possível dizer que a educação é invadida pelos discursos técnicos e que presencia-se a cientifização dos saberes sobre a criança. Isso tudo aliado a um discurso pedagógico normalizador fez da escola uma arena atravessada pelo discurso médico-psicológico corresponsável pelo crescente processo de patologização e medicalização da educação.

A categoria que tratou das questões metodológicas e tipos de pesquisas predominantes revelou que, dentre trinta artigos estudados nos estratos A1 e A2, treze utilizaram testes, escalas, avaliações padronizadas nacional e/ou internacionalmente para obter os objetivos propostos. Foi bem expressivo também o número de artigos (oito) que combinaram os testes padronizados e a comparação entre grupos. Desse conjunto, alguns fizeram alusão, em poucas linhas, sobre o como ensinar, porém em nenhum dos estudos observou-se o procedimento de ir à escola, avaliar o conteúdo programático, questionar as diretrizes educacionais, os padrões de idade para aprender a ler, a escrever, calcular, etc. Os testes, quando mal empregados - descontextualizados da realidade social, histórica e cultural e, inclusive, do ambiente educacional - tendem a uniformizar os indivíduos, desconsiderando singularidades, anulando subjetividades com base em modelos de comportamentos que são considerados típicos. Guarido (2010) nomeia de normalização das normatizações (tornar normal/esperado as normas/regras), dado que tem como consequência a patologização da educação, rotulando de doença tudo aquilo que escapa à norma e recorrendo às prescrições médicas para intervir nessas singularidades e comportá-las em subjetividades esperadas ou desejadas.

Dos trinta e um artigos analisados no estrato B1, treze se utilizaram de uma combinação que incluiu 
testes e comparação entre grupos. Tais estudos foram considerados não críticos, segundo o entendimento do que se põe como crítica (Patto, 1984, 1999, 2012; Meira, 2003, 2012b). Há ainda evidências de pesquisas que trabalham com um viés naturalista do desenvolvimento e aprendizagem e que, portanto, corroboram com a medicalização escolar. Apresentam um teor de contradição ao apresentarem o diagnóstico do transtorno de aprendizagem - cuja causa é anunciada como de ordem biológica - podendo ser construído por meio de diversos elementos:

O diagnóstico do TDAH fundamenta-se no quadro clínico comportamental, já que existe um marcador biológico especifico que contemple todos os casos desse transtorno. Não existe, portanto, nenbum teste psicométrico, neurológico ou laboratorial que permita diagnosticar o TDAH. O diagnóstico é o resultado da análise de informaçôes obtidas de várias fontes e em diversas situações, incluindo desde a queixa feita no consultório do profissional até as informações obtidas mediante entrevistas e escalas com os pais ou responsáveis, os professores e a anamnese da criança. (Jou, Amaral, Schaefer, \& Zimmer, 2010. p. 30 apud Guardiola, 2006; Low, 2006; Rota, 2006).

Reincidindo sobre uma concepção individualista de desenvolvimento e aprendizagem, os testes são utilizados como um recurso para pontuar sintomas, estes são classificados por meio de comparação com crianças da mesma idade escolar e, a partir de tal pontuação, os sintomas são qualificados como socialmente esperados, ou não, e assim, rotulados. (Jou et al., 2010. p. 30).

As análises dos artigos demonstraram que, para além da massiva utilização de testes, há uma junção dos testes psicométricos à comparação entre grupos. Em geral, há uma classificação a posteriori de alunos bem-sucedidos e fracassados; eles são divididos em dois grupos e, em seguida, os grupos são apresentados a um conjunto de informações denominada intervenção. Posteriormente novos testes são utilizados, confirmando que, à luz das informações devidas, o problema é mesmo da criança que não aprendeu, pois o grupo considerado de excelência o fez. Esse procedimento metodológico de pesquisa foi o mais encontrado dentre os quarenta e seis estudos considerados não críticos nos estratos A1, A2 e B1 em psicologia e educação. Tal instrumento de pesquisa se mostra ineficaz à medida que se rotula antes mesmo da aplicação do teste.

No conjunto de trinta e um artigos analisados em periódicos B1, sete estudos se utilizaram da revisão bibliográfica, com destaque para o fato de seis terem sido considerados como estudos críticos frente ao processo de medicalização escolar. Quanto à categoria Modos de intervenção, foi expressivo o número de artigos que não propõe intervenção (doze) e quando o fazem se atém ao nível do trabalho pedagógico individual (seis). A pesquisa levou a considerar que, ou não se pensa em "soluções" para superar essa epidemia de diagnósticos (Welch, Schwartz, \& Woloshin, 2008) ou se propõe um procedimento individual pedagógico. As análises conduziram a seguinte contradição: ao mesmo tempo em que alguns autores proclamam que a causa do fracasso pode ser biológica, se prescreve uma educação pedagógica como forma de superação, o que indica que tal forma de intervenção pode resultar positivamente, derrubando o caráter apriorístico e natural para a justificativa da (não) aprendizagem.

Por meio dessa categoria, buscou-se entender como os estudos analisados sugerem a ação profissional para o problema debatido. Dos trinta e um artigos analisados no estrato B1, treze propõem que a intervenção seja feita individualmente, com o aluno, em âmbito pedagógico ou psicológico. A categoria Modos de intervenção se mostrou, de fato, elucidativa na análise das pesquisas confirmando a correlação entre a conceptualização assumida para os problemas de aprendizagem e/ou transtorno do comportamento, a suposta causa do "transtorno" e o modelo de intervenção proposto pelo(s) pesquisador(es). A análise dos artigos sob as duas primeiras categorias revelou que quando a conceptualização do transtorno de aprendizagem era sustentada por um pressuposto biológico, com base num quadro representativo de sintomas e amparado por uma linguagem presente nos manuais diagnósticos, ou ainda quando os autores não demonstravam preocupação em assinalar o referencial teórico para determinado objeto de estudo, em geral, tais artigos sugeriam a intervenção individual, na área pedagógica ou psicoterapêutica.

Esse fato apresenta uma questão que merece ser debatida: a prática dos encaminhamentos individuais está entrelaçada a uma teoria que parece compreender o desenvolvimento do sujeito, ou a interrupção dele, como um processo evolutivo e individual. Segundo estudos de Collares e Moysés (1996, p.156), ainda hoje na educação se compreende aprendizado e desenvolvimento como independentes “(...) Admite-se a existência de uma relação unívoca: a aprendizagem depende do desenvolvimento, mas o curso do desenvolvimento não é afetado pela aprendizagem".

O encaminhamento de crianças com transtornos de aprendizagem para atendimento na área da saúde 
é uma prática que coloca em segundo plano a função social da escola e do professor como mediadores essenciais na superação das funções psicológicas naturais em direção ao desenvolvimento cultural (Vygotsky, 1996). Pode-se inferir que a sequência de publicações dos DSMs e a influência que eles exercem na pesquisa e na clínica médica e psicológica - já que ambas se organizam em função da intervenção direta sobre os sintomas - também contribuem para distanciar os contextos educativos e os modelos que se têm de aprendizagem da qualidade do processo de desenvolvimento alcançado pelo sujeito.

Em relação aos artigos críticos, dentro do conjunto analisado, argumenta-se que eles propõem um rompimento com os conceitos de transtornos de aprendizagem assinalando a preocupação com o uso de terminologias que rotulam e excluem quem está aquém do esperado. Mattos (2012, p. 220) traz para essa discussão a posição social ocupada por aqueles que são candidatos ao diagnóstico ou recebem o tratamento: “(...) a exclusão é um processo que atinge todas as camadas sociais, porém, com maior intensidade a camada popular (...)". Tais aspectos são convergentes com os achados de uma pesquisa em que Collares e Moysés (1996) buscaram nos discursos de diferentes profissionais da saúde e da educação, as concepções acerca do fracasso escolar situando a pobreza como a principal causa considerada.

Assim, para além da atenção aos modelos individuais de intervenção como uma proposta recorrente nos artigos pesquisados, é preciso questionar os modelos teóricos que embasam tal proposta e que as ciências humanas - particularmente a psicologia e a educação - têm se apropriado com o intuito de não se responsabilizarem pela aprendizagem e pelo desenvolvimento das crianças. Ainda acerca do sucesso ou fracasso escolar, Garrido e Moysés (2010, p. 149), evocam uma questão que tem se mostrado contraditória na teorização:

O que está em questão é a atribuição da responsabilidade pelo processo de ensino-aprendizagem à criança que aprende e não ao adulto que ensina. Para ser mais exata, à criança que não aprende, pois o êxito daquela que aprende é tido comumente como mérito de quem ensina. Aquela que não aprende, entretanto, é vista, há muito, como responsável por seu insucesso, seja em rąão de sua origem econômica, cultural ou, mais recentemente, de suas características biológicas.

Utilizar uma teoria que adere a maturação orgânica como pré-condição ao aprendizado parece conveniente nos casos de insucesso escolar. Porém, quando se trata do aluno-sucesso, a teoria ultrapassa aquilo que é considerado típico do amadurecimento biológico, e recorre aos méritos da instituição escolar e de todos os implicados na educação desse estudante.

\section{Considerações Finais}

Primeiramente cumpre destacar os limites do presente estudo que, ao analisar um conjunto de artigos que, em sua maioria, ainda reforçam argumentos distantes da complexidade que envolve as dificuldades escolares, também postula a necessidade de novos trabalhos que acompanhem a produção de pesquisas nas áreas da psicologia e da educação, relativos a essa temática, como forma de identificar as implicações do não aprender na escola para a formação humana.

A análise quantitativa e qualitativa de sessenta e um artigos demonstrou que apenas quinze apresenta um posicionamento crítico frente ao fenômeno da medicalização na educação alocados nas seguintes áreas e substratos: A1 (Dois críticos - um em educação e um em psicologia); A2 (Quatro críticos - um em educação e três em psicologia) e B1 (nove críticos - quatro em educação e cinco em psicologia). Os estudos críticos em periódicos de psicologia e educação conformam um conceito ampliado que extrapola a dimensão individual e abarca outros elementos constitutivos das dificuldades que se originam na esfera educacional fomentando a medicalização.

O estudo permitiu constatar que a maioria das pesquisas acerca dos denominados transtornos de aprendizagem trata de acentuar o caráter biológico de mecanismos considerados importantes para a aprendizagem - como a atenção e a memória - o que levaria à patologia quando o aluno não apresenta tais funções psíquicas já desenvolvidas. A pesquisa tornou evidente uma forte correlação entre as metodologias aplicadas, as propostas de intervenção e a conceptualização dos chamados transtornos de aprendizagem.

No conjunto de estudos críticos destacados no triênio 2010-2012, quatro se utilizaram do aporte Histórico-Cultural para se contrapor às ideias que nutrem a perspectiva medicalizante, prática corrente em nossa sociedade. Tendo em vista encontrar, nos fundamentos da Psicologia Histórico-Cultural, elementos capazes de romper com esse ideário os autores desse conjunto de artigos (Meira, 2012a; Leite \& Tuleski, 2011; Eidt \& Tuleski, 2010; Rossato \& Leonardo, 2012) deram visibilidade ao desenvolvimento da atenção voluntária e o autocontrole do comportamento como processos 
- dentre outros - em constante superação dialética, em que funções psíquicas naturais transformam-se em funções psíquicas culturais (ou superiores).

Nesse sentido, a escola foi referida como um importante espaço de formação social do psiquismo, uma vez que é por meio da prática pedagógica escolar que se ativa uma série de processos psíquicos, originalmente naturais. Daí a inversão do ideário organicista que, ao privilegiar os processos maturacionais, diminui a interferência educacional nos processos de ensino, de aprendizagem e desenvolvimento.

A concepção organicista se apresentou como mais uma teoria que reafirma a medicalização escolar e a consequente patologização da vida, na medida em que pensa os processos psíquicos como algo biológico que encontra apoio no campo individual, responsabilizando unicamente o sujeito pelo seu desenvolvimento e sucesso, ou insucesso, escolar. "O movimento dialético entre vivenciar, aprender e desenvolver, segundo os estudos de Vygotski, confere possibilidades revolucionárias no processo ensino-aprendizagem que deve ocorrer na escola" (Collares \& Moysés, 1996, pág. 156).

Contrariando preceitos da psicologia idealista contidos em inúmeros estudos avaliados, as inquietantes discussões propostas por artigos críticos colocam na ordem do dia outros questionamentos, dentre eles a eficácia das políticas públicas dirigidas à área da educação que tem afetado diretamente as camadas mais empobrecidas da população, usuárias de uma escola precarizada, os métodos pedagógicos de ensino-aprendizagem propostos e a dinâmica institucional que conformam a produção das queixas escolares - traduzidas por Transtorno de Déficit de Atenção e Hiperatividade - TDAH - Transtorno de Oposição e Desafio - TOD, dislexias, disgrafias e tantos outros - e dos encaminhamentos de escolares a diferentes setores da saúde.

O estudo demonstrou que convivemos, atualmente, com o risco de que tudo isso nem sequer seja questionado porque sucumbe a uma análise superficial da situação das crianças e de suas famílias, análise essa que parece estar representada pela adesão da academia a um prognóstico que situa no corpo dos sujeitos os problemas relativos à sua não-aprendizagem escolar. As concepções e práticas relativas aos problemas de aprendizagem e de comportamento adotadas pelos artigos científicos analisados, em sua maior parte, permanecem as mesmas da primeira metade do século $\mathrm{XX}$, quando a psicologia começou a ser introduzida no contexto educacional brasileiro e a intervenção se dava na forma de orientações a professores e familiares, além de serem direcionadas a própria criança no sentido da modificação de hábitos, condutas, sem, no entanto, qualquer questionamento quanto às condições materiais, econômicas e sociais em que tais dificuldades escolares emergiam.

Foi encontrado um número expressivo de artigos que tendem a psicologização da vida, a patologização do sujeito e a consequente medicalização de crianças e jovens estudantes, culpabilizando-os por apresentar diferenças ou especificidades nas maneiras de se relacionar com os conteúdos e métodos escolares. Tais artigos questionam pouco, ou quase nada, a conjuntura político-econômica e social na qual tais sujeitos estão submersos, a condição burguesa e elitista que baliza e normatiza a vida, a qualidade educacional situada na sociedade brasileira "sob o signo do descaso" (Patto, 2010) e a falta de diálogo e de parcerias entre escola e demais instâncias educacionais, dentre elas a família que, ao arrebatarem o discurso médico, se submetem à verdade científica incontestável convergindo para $\mathrm{o}$ encaminhamento aos especialistas que fortalecem a ideia da medicalização escolar.

A prevalência de um conjunto de artigos não-críticos demonstrou que ainda convivemos com uma ciência que, distante de uma concepção crítica, no sentido materialista histórico e dialético formulado por Martins (1977, apud Patto, 2012), não permite questionar os processos medicalizantes tão presentes no campo da educação. Além disso, o que tais estudos, em sua maioria, deixaram de sublinhar é que além de rotular e prescrever, o processo de medicalização da educação tem funcionado como um importante marcador social, discriminando negativamente e convertendo desigualdades econômicas e de classe social, em diferenças e singularidades individuais, marcadas com o rótulo de doenças psíquicas ou distúrbios comportamentais.

\section{Referências}

Angelucci, C. B., \& Souza, B. de Paula (2010). Medicalização de crianças e adolescentes: conflitos silenciados pela redução de questões sociais a doenças de indivíduos. São Paulo: Casa do Psicólogo.

Angelucci, C. B., Kalmus, J., Paparelli, R., \& Patto, M.H.S (2004). O estado da arte da pesquisa sobre o fracasso escolar (1991-2002): Um estudo introdutório. Revista Educação e Pesquisa, São Paulo, 30(1), 51-72. doi: 10.1590/S1517-97022004000100004 
Associação Psiquiátrica Americana. (1980). Manual diagnóstico e estatístico de transtornos mentais. ( $4^{\mathrm{a}} \mathrm{ed}$.). Porto Alegre: Artes Médicas.

Caliman, L. V. (2010) Notas sobre a história oficial do transtorno do déficit de atenção/hiperatividade TDAH. Psicologia, ciência e profissão, 30(1), 45-61. doi: 10.1590/S1414-98932010000100005

Castilho, P. T. (2012). Formas de mal-estar no campo da educação: Sintoma, inibição e angústia nos fracassos escolares. Revista Psic. da Ed., São Paulo, 34(1), 20-36. Recuperado de http://pepsic.bvsalud.org/ pdf/psie/n34/n34a03.pdf

Chauí, M. S. Cultura e democracia. São Paulo: ed. Cortez, 1997.

Chauí, M. S. O que é ideologia. São Paulo: ed. Brasiliense, $31^{\text {a }} .$. ed., 1980.

Coordenação de Aperfeiçoamento de Pessoal de Nível Superior - CAPES (2013). Recuperado de http:/ / www.capes.gov.br/36-noticias/6439-atualizacaofinal-do-qualis-periodicos-para-a-avaliacao-trienal-2013

Collares, C. A. L., \& Moysés M. A. (Eds.) (1996). Por que as crianças não aprendem? Em Preconceitos no cotidiano escolar - ensino e medicalização. São Paulo: Editora Cortez.

Eidt, N. M., \& Tuleski, S.C. (2010). Transtorno de déficit de atenção/hiperatividade e Psicologia HistóricoCultural. Cadernos de Pesquisa, 40(139) 121-146. doi: 10.1590/S0100-15742010000100007

Ferreira, N. S. A. (2002). As pesquisas denominadas "Estados da Arte". Revista Educação \& Sociedade, ano XXIII, 79, 257-272. Recuperado de http://www. scielo.br/pdf/es/v23n79/10857.pdf

Fórum sobre medicalização da educação e da sociedade (2010). Manifesto do Fórum sobre Medicalização da Educaşão e da Sociedade. Recuperado de http:// medicalizacao.org.br/manifesto-do-forum-sobre-medicalizacao-da-educacao-e-da-sociedade/

Garrido, J., \& Moysés, M. A. A. (2010). Um panorama nacional dos estudos sobre a medicalização da aprendizagem de crianças em idade escolar. Em Conselho Regional de Psicologia de São Paulo. Medicalização de crianças e adolescente: Conflitos silenciados pela redução de questões sociais a doenças de indivíduos (pp. 149-161). São Paulo: Casa do Psicólogo.
Guarido, R. (2010). A biologização da vida e algumas implicações do discurso médico sobre a educação. Em Conselho Regional de Psicologia de São Paulo, Grupo Interinstitucional Queixa Escolar (Eds.). Medicalização de crianças e adolescentes: conflitos silenciados pela redução de questões sociais a doença de indivíduos (pp. 27-39). São Paulo: Casa do Psicólogo.

Jou, G. I., Amaral, B., Pavan, C. R., Schaefer, L. S., \& Zimmer, M. (2010). Transtorno de déficit de atenção e hiperativa: Um olhar no ensino fundamental. Psicologia: Reflexão e Crítica, 23(1), 29-36. doi: 10.1590/S0102-79722010000100005

Leite, H. A., \& Tuleski, S. C. (2011). Psicologia histórico-cultural e desenvolvimento da atenção voluntária: Novo entendimento para o TDAH. Psicologia escolar e educacional, 15(1), 111-119. Recuperado de http:// www.scielo.br/pdf/pee/v15n1/12.pdf

Massi, G., \& Santana, A. P. O. (2011). Desconstrução do conceito de dislexia. Paideia, 21(50), 403-411. Recuperado de http://www.scielo.br/pdf/paideia/v21n50/13.pdf

Mattos, S. M. N. (2012). Inclusão/ exclusão escolar e afetividade: repensando o fracasso escolar das crianças de classes populares. Educar em Revista, 44(1),217-233, Recuperado de http://www.scielo. br/pdf/er/n44/n44a14.pdf

Meira, M. E. M. (2000). Psicologia escolar: Pensamento crítico e práticas profissionais. Em E. R. Tanamachi, M. P. R. Souza \& M. L. Rocha (Eds.). Psicologia e Educação: desafios teórico-práticos. São Paulo: Casa do Psicólogo.

Meira, M. E. M. (2003). Construindo uma concepção crítica de psicologia escolar: contribuições da Pedagogia Histórico-crítica e da Psicologia Sócio-Histórica. Em M. E. M. Meira \& M. A. M. Antunes (Eds.). Psicologia Escolar: Teorias Críticas (pp. 13-78). São Paulo: Casa do Psicólogo.

Meira, M. E. M. (2012a). Para uma crítica da medicalização na educação. Revista da Associação Brasileira de Psicologia Escolar e Educacional - ABRAPEE, 16(1), (pp. 135-142). doi: 10.1590/ S1413-85572012000100014

Meira, M. E. M. (2012b). A crítica da Psicologia e a tarefa da crítica na Psicologia. Psicologia Política, 12(23), 13-26. Recuperado de http://pepsic. bvsalud.org/scielo.php?script $=$ sci_pdf\&pi- 
$\mathrm{d}=$ S1519549X2012000100002\&lng=pt\&nrm =iso\&tlng $=\mathrm{pt}$

Moysés, M. A. A., \& Collares, C. A. L. (2010). Dislexia e TDAH: Uma análise a partir da ciência médica. Em Conselho Regional de Psicologia de São Paulo; Grupo Interinstitucional Queixa Escolar. Medicalização de crianças e adolescente: conflitos silenciados pela redução de questões sociais a doença de indivíduos. (pp. 71110). São Paulo: Casa do Psicólogo.

Organização Mundial da Saúde. (1996). Classificação Estatística Internacional de Doenças e Problemas Relacionados à Saúde: CID-10 Décima revisão. Trad. do Centro Colaborador da OMS para a Classificação de Doenças em Português. ( $3^{a}$ ed). São Paulo: EDUSP.

Patto, M. H. S. (Eds.). (1984). Psicologia e ideologia: Uma introdução crítica à psicologia escolar. São Paulo: T. A. Queiroz.

Patto, M. H S. (Eds.). (1999). A Produção do fracasso escolar: Histórias de submissão e rebeldia. São Paulo: T. A. Queiroz.

Patto, M. H. S. (Eds.). (2000). Mutações do cativeiro: Escritos de psicologia e política. São Paulo: Hacker editores /Edusp.

Patto, M. H. S. (Eds.). (2010). Sob o signo do descaso. Em A cidadania negada: politicas públicas e formas de viver (182-189). São Paulo: Casa do Psicólogo.

Patto, M. H. S. (Eds.). (2012). Formação de psicólogos e relacões de poder: Sobre a miséria da psicologia. São Paulo: Casa do Psicólogo.

Rodríguez, M. C., Campos, A. P. S., \& Fernandes, I. A. (2012) Caracterização da queixa escolar no Centro de Psicologia Aplicada da Universidade Federal de Juiz de Fora. Estudos de Psicologia, Campinas, 29(2), 241-251. doi: 10.1590/S0103-166X2012000200010

Rossato, S. P. M., \& Leonardo, N. S. T. (2012). A queixa escolar na perspectiva de educadores da Educação
Especial. Revista Semestral da Associação Brasileira de Psicologia Escolar e Educacional. São Paulo, 16(1), 1523. doi: 10.1590/S1413-85572012000100002

Souza, M. P. R. (2010). Retornando à patologia para justificar a não aprendizagem escolar: A medicalização e o diagnóstico de transtornos de aprendizagem em tempos de neoliberalismo. Em Conselho Regional de Psicologia de São Paulo; Grupo Interinstitucional Queixa Escolar. Medicalização de crianças e Adolescentes: conflitos silenciados pela redução de questões sociais a doenças de indivíduos (pp. 57-67). São Paulo: Casa do Psicólogo.

Viégas, L. S., \& Oliveira, A. R. F. (2014). TDAH: Conceitos vagos, existência duvidosa. Nuances, 25(1), 39-58. doi: 10.14572/nuances.v25i1.2736

Vygotsky, L. S. (1996). A formação social da mente (7 ed.). Rio de Janeiro: Martins Fontes.

Welch, G., Schwartz, L., \& Woloshin, S. (2008). O que está nos deixando doentes é uma epidemia de diagnósticos. Em Conselho Regional de Medicina do Estado de São Paulo (CREMESP). Jornal do Cremesp Laboratórios (JC pág. 12). Ed. 245 (2). (Original publicado em 2007). Tradução de Daniel de Menezes Pereira. Recuperado de http://www.cremesp. org.br/?siteAcao $=$ Jornal\&id $=954$

Zibetti, M. L. T., Souza, F. L. F., \& Queiróz K. J. M. (2010). Quando a escola recorre à psicologia: Mecanismos de produção, encaminhamento e atendimento à queixa na alfabetização. Estudos e pesquisas em Psicologia, Rio de Janeiro 10(2), 490-506. doi: 10.12957/epp.2010.8979

Recebido em: 25/01/2016

Reformulado em: 16/06/2016;07/07/2016

Aprovado em: 08/08/2016 
Sobre as autoras:

Cláudia Ap. Valderramas Gomes é graduada em Psicologia pela Universidade Estadual Paulista Júlio de Mesquita Filho - UNESP, campus de Bauru-SP, mestre e doutora em Educação pela UNESP, campus de Marília-SP e professora assistente doutora do Departamento de Psicologia Evolutiva, Social e Escolar - Curso de Graduação - e do Programa de Pós-Graduação em Psicologia da Faculdade de Ciências e Letras da UNESP, campus de Assis-SP.

E-mail: cabegomes@uol.com.br

Naeli Simoni-Castro é graduada em Psicologia pela Universidade Estadual Paulista Júlio de Mesquita Filho - UNESP, campus de Assis-SP e mestranda no Programa de Pós-Graduação em Psicologia da Faculdade de Ciências e Letras da mesma universidade, área de concentração Psicologia e Sociedade.

E-mail:naeli_castro@hotmail.com

\section{Contato com as autoras:}

Cláudia Ap. Valderramas Gomes

Rua Antonio do Espírito Santo, 8-18

Bauru-SP, Brasil

CEP: 17051-180 